\title{
SISTEM INFORMASI EVALUASI MUTU AKADEMIK DAN PROSES PEMBELAJARAN MENGGUNAKAN METODE ENHANCED CUMULATIVE VOTING
}

\author{
Aris Eko Priyanto ${ }^{1}$, Achmad Jauhari ${ }^{2}$, Rika Yunitarini ${ }^{3}$ \\ ${ }^{1,2,3}$ Program Studi Teknik Informatika-Fakultas Teknik, Universitas Trunojoyo \\ Kampus Unijoyo, Kamal - Telang, Bangkalan Madura \\ ${ }^{1}$ aris.winchester@gmail.com
}

\begin{abstract}
ABSTRAK
Untuk meningkatkan kualitas pengajaran di Universitas Trunojoyo diperlukan adanya evaluasi pembelajaran. Salah satu caranya adalah dengan membuat survei. Peserta survei adalah mahasiswa dan hasilnya diinput ke tim penjaminan mutu. Kondisi pengisian dan rekapitulasi survei saat ini dilakukan dengan menulis di atas kertas sehingga Anda akan membuat sistem elektronik dari pengisian rekapitulasi. Metode yang digunakan saat ini adalah voting kumulatif. Metode ini mudah dan cepat diterapkan. Namun, hasilnya kurang bisa diandalkan. Dikarenakan pada metode Pemungutan Suara Kumulatif tidak melihat latar belakang objek yang berkontribusi terhadap kualitas akademik dalam hal ini adalah mahasiswa. Oleh karena itu dalam pembahasan kali ini akan digunakan metode Cumulative Voting Enhanced yang selanjutnya disingkat menjadi (ECV). Dimana metode ini meningkatkan kualitas hasil Pemungutan Suara Kumulatif dengan cara mengelompokkan objek siswa menjadi beberapa kriteria yaitu berlaku, jumlah kehadiran, status mata kuliah yang diambil dan lamanya waktu pengisian formulir. Setelah siswa dikelompokkan, maka akan dilakukan pembobotan menggunakan Analytical Hierarchy Process skala 1-9. Dengan menggunakan ECV maka hasil evaluasi diharapkan mendekati kenyataan karena tampilan pengelompokan berdasarkan kriteria.
\end{abstract}

Kata kunci: AHP, Voting Kumulatif, bobot, metode pemeringkatan

\begin{abstract}
To improve the quality of teaching at the University Trunojoyo Informatics Engineering is required for the evaluation of learning. One way is to create a survey. Survey participants were students and the results are input into the quality assurance team. Charging conditions and the recapitulation of the current survey is done by writing on paper so that you will be creating an electronic system from filling up the recapitulation. The method used today is the cumulative voting. The method is easy and quick to implement. However, the results are less reliable. Due to the method of Cumulative Voting does not see the background object that contribute to academic quality in this case is a student. Therefore in this discussion will use the methods of Cumulative Voting Enhanced hereinafter abbreviated as (ECV). Where this method of improving the quality of the results of Cumulative Voting by way of classifying objects students into several criteria, namely in force, the number of attendance, the status of the courses taken and the length of time filling the form. Once students are grouped, it will be weighted using Analytical Hierarchy Process scale of 1-9. By using ECV then the results of the evaluation are expected to be close to reality because the look of the grouping based on the criteria.
\end{abstract}

Keywords: AHP, Cumulative Voting, weights, method of ranking. 


\section{PENDAHULUAN}

Ciri pendidikan berkualiatas adalah pendidikan yang selalu melakukanevaluasi hasil be ajar setiap selesai sat semester at au sat period pembelajaran.Salah sat evaluasi yang digunakan adalah evaluasi dari sisi obyek pembelajaran yakni peserta ajar dimana peserta ajar yakni mahasiswa melakukan penilaian kinerja dosen dalam hal pelayanan kepada mahasiswa yang meliputi persiapan pengajaran, penyampaian materi, pengayaan materi dan sebagainya.

Pada program studi teknik informatika universitas Trunojoyo Madura setiap tahunnya melakukan sistem evaluasi yang dilaksanakan dan di awasi langsung oleh tim jaminan mutu program studi. Setiap mahasiswa aktif diminta untuk mengisi form evaluasi pada saat ujian akhir semester.

Permasalahan yang terjadi adalah ketika berhubungan dengan jumlah data dan variasi data yang masuk. Dimana setiap selesai evaluasi pembelajaran sat period, data yang masuk pada tim jaminan mutu berjumlah ratusan hingga ribuan data. Dan datadata tersebut adalah bersifat manual, yakni tertulis di kertas. Tim jaminan mutu harus melakukan rekapitulasi manual per mata kuliah, per dosen, dan melakukan penilaian hasil.

Tentu ini menyulitkan tim jaminan mutu, dan faktanya dari observasi lapangan adalah sudah 2 period pembelajaran berturut-turut tidak dilakukan evaluasi pembelajaran dikarenakan data yang masuk banyak dan tidak sempat terselesaikan sebagian besar. Jelas ini merugikan program studi dikarenakan tidak ada masukan dari sisi mahasiswa mengenai masukan untuk peningkatan kualitas mutu akademik.

Dari sisi metode yang digunakan juga kurang mendekati hasil kenyataan, yakni menggunakan metode Cumulative Voting. Dimana dalam form terdapat pertanyaan dan 4 pilihan jawaban. Dan 4 pilihan jawaban tersebut memiliki nilai yang tidak sama.
Kekurangan dari metode ini adalah tidak melihat sisi obyek pembelajaran yakni mahasiswa, karena latar belakang, dan motivasi mahasiswa bergantung pada beberapa hal. Kebanyakan mahasiswa ketika mengisi form dapat tidak menunjukan suara sebenarnya dari mahasiswa. Hal ini dikarenakan mahasiswa memilih untuk cepat mengisi dan menyelesaikan. Masalah tersebut sering terjadi pada mahasiswa angkatan lama baik yang mengulang mata kuliah ataupun tidak. Dan ini menjadi semacam tradisi bagi mahasiswa di angkatan bawah.

\section{METODE}

\section{A. Cumulative Votting}

Cumulative Voting (CV) adalah salah satu metode tertua dan paling mudah digunakan untuk memprioritaskan requirement. Para customer atau kelompok customer disediakan 100 unit (poin, uang atau unit imajiner lainnya) untuk mendistribusikan di antara requirement[3]. Semakin banyak poin yang diberikan pada suatu requirement tertentu, semakin tinggi prioritas requirement tersebut. Sangat mudah untuk mendistribusikan 100 poin ketika memiliki beberapa requirement. Tapi, ketika semakin banyak requirement, $\mathrm{CV}$ mulai kehilangan keasliannya. Misalnya memiliki 50 requirement, dan kemudian customer tidak dapat memberikan lebih dari 2 poin untuk setiap requirement (jika dia ingin memberikan poin yang eksplisit untuk semua requirement). Dalam hal ini, sulit untuk memperkirakan kepentingan relatif antara requirement.

\section{B. Analytical Hierarchy Process}

Adalah metode yang dikembangkan oleh Saaty yang digunakan untuk pengambilan keputusan dengan memperhatikan faktor kesukaan, persepsi, pengalaman dan intuisi. AHP dapat digunakan untuk membantu menganalisa dan memberi masukan dalam pengambilan keputusan dengan menggunakan skala 1 - 9 AHP berikut: 
Tabel 1. Skala AHP

\begin{tabular}{|c|l|}
\hline $\begin{array}{c}\text { Skala } \\
\mathrm{a}_{\mathrm{bc}}\end{array}$ & \multicolumn{1}{|c|}{ Penjelasan } \\
\hline 1 & b dan c sama-sama penting \\
\hline 3 & $\begin{array}{l}\text { b sedikit lebih penting daripada } \\
\mathrm{c}\end{array}$ \\
\hline 5 & b lebih penting dari c \\
\hline 7 & $\begin{array}{l}\text { b sangat lebih penting daripada } \\
\mathrm{c}\end{array}$ \\
\hline 9 & $\begin{array}{l}\text { b benar-benar lebih penting } \\
\text { daripada c }\end{array}$ \\
\hline $2,4,6,8$ & Nilai tengah \\
\hline
\end{tabular}

C. Enhanced Cumulative Votting (ECV)

Pada dasarnya desain prosedur metode ECV dimulai dengan langkah awal yang sama dengan $\mathrm{CV}$, yaitu memastikan spesifikasi requirement. Selengkapnya dapat dilihat pada Gambar 1.

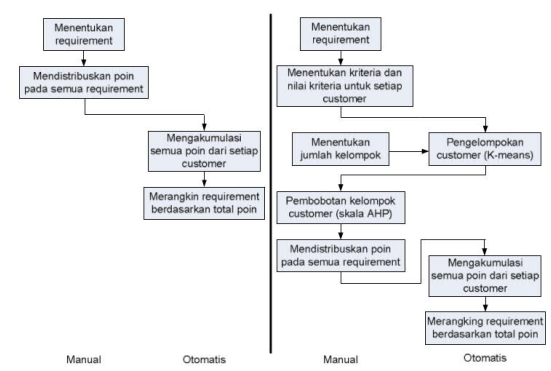

Gambar_1. Perbandingan Desain Sistem CV dan ECV

Sedangkan prosedur berikutnya adalah sebagai berikut:

1. Menentukan kriteria dan nilai

kriteria untuk setiap customer.

Pengujian dalam penelitian ini menggunakan 2 kriteria untuk memudahkan visualisasi pengelompokan pada diagram kartesius. Jumlah kriteria yan digunakan bisa satu, dua atau tiga, dan seterusnya sesuai keinginan. Penentuan kriteria bisa ditentukan berdasarkan faktor-faktor yang mempengaruhi kontribusi customer terhadap sistem, misalnya: jumlah kebutuhan fungsional sistem, jumlah pengguna untuk kategori customer, kontribusi keuntungan, kontribusi biaya, dan sebagainya. Pengukuran nilai faktor bisa diambil dari data lapangan yang memenuhi syarat untuk digunakan sebagai kriteria dalam pengelompokan. Pengelompokan Mahasiswa.

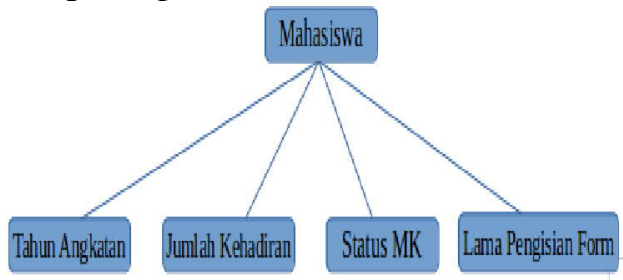

Gambar_2. Pengelompokan Mahasiswa

Untuk meningkatkan kualitas pembelajaran pada prodi Teknik Informatika Universitas Trunojoyo Madura, maka kepala jaminan mutu melakukan evaluasi kinerja pelayanan dosen terhadap mahasiswa. Dalam hal ini, mahasiswa dikelompokan dengan kriteria berdasarkan kesepakatan tim jaminan mutu dan kepala jurusan yang sudah dibahas pada point 7.4 diatas sebagai berikut:

2. Pembobotan kelompok customer

Kelompok (cluster) yang sudah didapat dari K-means harus diberikan bobot. Pemberian bobot untuk setiap kelompok di sini bisa dilakukan dengan bebas tetapi dalam metode ECV ini mengadopsi metode AHP yang menggunakan skala 1 sampai 9 (antara 0 dan 10), sehingga aturan skala yang digunakan juga sama. Penjelasan skala bobot dalam ECV dijelaskan dalam Tabel 2. Nilai bobot dalam sebuah kelompok menunjukkan besarnya kontribusi (pengali) terhadap poin yang diberikan customer yang masuk dalam kelompok tersebut. Nilai bobot yang bisa diberikan dalam jangkauan 1 sampai 9 .

Table 2. skala dasar perbandingan berpasangan $\mathrm{ECV}$

\begin{tabular}{|c|l|}
\hline Bobot & \multicolumn{1}{c|}{ Definisi } \\
\hline 1 & Kontribusi sangat ekstrim kecil \\
\hline 3 & Kontribusi agak kecil \\
\hline 5 & Kontribusi sedang-sedang saja \\
\hline 7 & Kontribusi agak besar \\
\hline 9 & $\begin{array}{l}\text { Kontribusi sangat ekstrim } \\
\text { besar }\end{array}$ \\
\hline
\end{tabular}


\begin{tabular}{|l|l|}
$2,4,6,8$ & $\begin{array}{l}\text { Nilai tengah di antara dua nilai } \\
\text { kontribusi yang berdekatan }\end{array}$ \\
\hline
\end{tabular}

\section{HASIL DAN PEMBAHASAN}

\section{Sistem Requirement}

Sebelum membangun sistem maka dilakukan wawancara kepada pihak-pihak terkait atau stake holder guna mendapatkan informasi dan detail apa saja yang dapat dilakukan oleh aplikasi yang dibangun. Pihak terkait yang digali datanya melalui wawancara adalah

1. Kepala Tim Jaminan Mutu Program Studi Teknik Informatika

2. Tim Jaminan Mutu Program Studi Teknik Informatika

3. Dosen Program Studi Teknik Informatika

4. Mahasiswa Program Studi Teknik Informatika

Menghasilkan detail requirement sebagai berikut.

Tabel 3. Stake Holder Requirement

\begin{tabular}{|c|c|}
\hline $\begin{array}{c}\text { Stake } \\
\text { Holder }\end{array}$ & Sistem Requirement \\
\hline $\begin{array}{c}\text { Jaminan } \\
\text { Mutu }\end{array}$ & $\begin{array}{l}\text { Sistem yang dibangun } \\
\text { memiliki: } \\
\text { 1. Akses login dan } \\
\text { tingkatan hak akses } \\
\text { adalah mahasiswa, } \\
\text { dosen dan admin / tim } \\
\text { jaminan mutu. } \\
\text { 2. Mengatur pertanyaan, } \\
\text { jawaban dan bobot } \\
\text { kuisioner. } \\
\text { 3. Mengatur KPI. } \\
\text { 4. Mengatur Metode } \\
\text { yang digunakan } \\
\text { 5. Management user } \\
\text { login tim jamu. } \\
\text { 6. Data kuisioner } \\
\text { dikelompokan secara } \\
\text { global, per dosen, dan } \\
\text { per mata kuliah. } \\
\text { 7. Sistem dapat } \\
\text { mengolah hasil } \\
\text { kuisioner sehingga } \\
\text { dapat menghasilkan } \\
\text { index prestasi dosen } \\
\text { berdasarkan }\end{array}$ \\
\hline
\end{tabular}

\begin{tabular}{|c|l|}
\hline & kuisioner. \\
\hline \multirow{5}{*}{ Dosen } & $\begin{array}{l}\text { 1. Login } \\
\text { 2. Melihat hasil } \\
\text { kuisioner berdasarkan } \\
\text { dosen dan kelas yang } \\
\text { di ampu. } \\
\text { 3. Data hasil kuisioner } \\
\text { yang dilihat dapat } \\
\text { berupa tabel angka } \\
\text { dan juga grafik } \\
\text { diagram batang. }\end{array}$ \\
\hline Mahasiswa & $\begin{array}{l}\text { 1. Login } \\
\text { 2. Mengisi kuisioner } \\
\text { berdasarkan mata } \\
\text { kuliah yang di ambil. }\end{array}$ \\
\hline Dari & hasil requirement diatas \\
\hline
\end{tabular}

maka dapat digambarkan uses case seperti berikut:

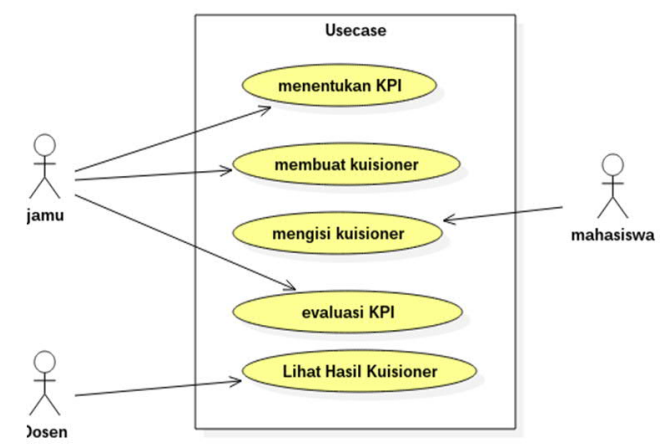

Gambar 3. Usescase.

Dan berikut gambaran dari usescase interaction.

Table 4. Usescase interaction.

\begin{tabular}{|c|c|}
\hline Uses & System \\
\hline \begin{tabular}{ll} 
Jamu : \\
1. & Login \\
2. & Input KPI \\
3. & Membuat \\
& Kuisioner \\
4. & Evaluasi \\
& KPI \\
Mahasiswa : \\
1. & Login \\
2. & Input \\
\multicolumn{2}{|c}{ Kuisioner } \\
Dosen : \\
1. & Login \\
2. & Evaluasi \\
& Hasil
\end{tabular} & $\begin{array}{l}\text { 1. Auntentifikasi } \\
\text { 2. Simpan } \\
\text { 1. Auntentifikasi } \\
\text { 2. Tampil data } \\
\text { hasil kuisioner }\end{array}$ \\
\hline
\end{tabular}

2. Key Performance Indicator

Kuisioner dibangun berdasarkan 
pertanyaan-pertanyaan.

Setiap

pertanyaan memiliki 4 pilihan jawaban. Setiap jawaban memiliki bobot / nilai yang berbeda. Masing-masing pertanyaan dalam kuisioner memiliki tujuan untuk mengukur kinerja dosen mengajar dalam kelas. Acuan dalam membuat pertanyaan kuisioner di atur oleh kunci performa indikator / key performance indicator. Berikut adalah tabel Key Performance Indicators dari tim jaminan mutu prodi Teknik Informatika Universitas Trunojoyo Madura.

Tabel 5. Key Performance Indicator.

\begin{tabular}{|c|c|c|c|}
\hline No & Area Kinerja & $\begin{array}{c}\text { Key } \\
\text { Performance } \\
\text { Indicator }\end{array}$ & $\begin{array}{c}\text { Bobot } \\
\text { KPI }\end{array}$ \\
\hline \multirow[t]{2}{*}{1} & $\begin{array}{l}\text { Perencanaan } \\
\text { Pembelajaran }\end{array}$ & $\begin{array}{l}\text { \% Jumlah } \\
\text { dosen yang } \\
\text { melakukan } \\
\text { perencanaan } \\
\text { pembelajaran } \\
\text { per mata } \\
\text { kuliah per } \\
\text { semester. }\end{array}$ & 15 \\
\hline & $\begin{array}{l}\text { Pelaksanaan } \\
\text { Pembelajaran }\end{array}$ & $\begin{array}{l}\text { \% jumlah } \\
\text { perencanaan } \\
\text { kuliah yang } \\
\text { sudah } \\
\text { terlaksana } \\
\text { dalam satu } \\
\text { semester. }\end{array}$ & 10 \\
\hline 2 & $\begin{array}{l}\text { Metode } \\
\text { Pembelajaran }\end{array}$ & $\begin{array}{l}\text { \% Jumlah } \\
\text { variasi metode } \\
\text { pembelajaran } \\
\text { dosen dalam } \\
\text { perkuliahan }\end{array}$ & 10 \\
\hline \multirow[t]{2}{*}{3} & $\begin{array}{l}\text { Metode } \\
\text { Penyampaian } \\
\text { materi }\end{array}$ & $\begin{array}{l}\% \text { jumlah } \\
\text { dosen yang } \\
\text { mendapat } \\
\text { predikat dosen } \\
\text { menarik - } \\
\text { sangat } \\
\text { menarik dalam } \\
\text { penyampaian } \\
\text { materi }\end{array}$ & 10 \\
\hline & $\begin{array}{l}\text { Mahasiswa } \\
\text { dalam } \\
\text { menyerap } \\
\text { materi }\end{array}$ & $\begin{array}{l}\text { \% jumlah } \\
\text { mahasiswa } \\
\text { yang } \\
\text { memahami } \\
\text { materi yang } \\
\text { disampaikan }\end{array}$ & 15 \\
\hline
\end{tabular}

\begin{tabular}{|c|c|c|c|}
\hline & & oleh dosen & \\
\hline \multirow[b]{2}{*}{4} & $\begin{array}{l}\text { Relveansi } \\
\text { Pokok } \\
\text { Bahasan mata } \\
\text { kuliah }\end{array}$ & $\begin{array}{l}\% \text { jumlah } \\
\text { pokok bahasan } \\
\text { yang relevansi } \\
\text { dengan mata } \\
\text { kuliah }\end{array}$ & 10 \\
\hline & $\begin{array}{l}\text { Materi } \\
\text { perkuliahan } \\
\text { terbaru / up to } \\
\text { date }\end{array}$ & $\begin{array}{l}\% \text { materi } \\
\text { dosen } \\
\text { memberikan } \\
\text { materi } \\
\text { perkuliahan } \\
\text { yang terbaru. }\end{array}$ & 5 \\
\hline 5 & $\begin{array}{l}\text { Ketepatan } \\
\text { waktu } \\
\text { perkuliahan }\end{array}$ & $\begin{array}{l}\% \text { dosen tepat } \\
\text { waktu dalam } \\
\text { datang } \\
\text { mengajar, } \\
\text { selesai } \\
\text { mengajar. }\end{array}$ & 10 \\
\hline \multirow[b]{2}{*}{6} & $\begin{array}{l}\text { evaluasi } \\
\text { tugas/uts/uas } \\
\text { yang } \\
\text { memadai }\end{array}$ & $\begin{array}{l}\% \\
\text { tugas/uts/uas } \\
\text { dibahas dan } \\
\text { dievaluasi } \\
\text { oleh dosen } \\
\text { kepada } \\
\text { mahasiswa. }\end{array}$ & 5 \\
\hline & $\begin{array}{l}\text { Keadilan } \\
\text { dalam } \\
\text { evaluasi dan } \\
\text { penilaian } \\
\text { tugas/uts/uas }\end{array}$ & $\begin{array}{l}\% \text { dosen } \\
\text { berlaku adil } \\
\text { dalam } \\
\text { melakukan } \\
\text { evaluasi dan } \\
\text { penilaian } \\
\text { terhadap } \\
\text { tugas/uts/uas } \\
\text { mahasiswa. }\end{array}$ & 10 \\
\hline & & & 100 \\
\hline
\end{tabular}

\section{Sistem ECV}

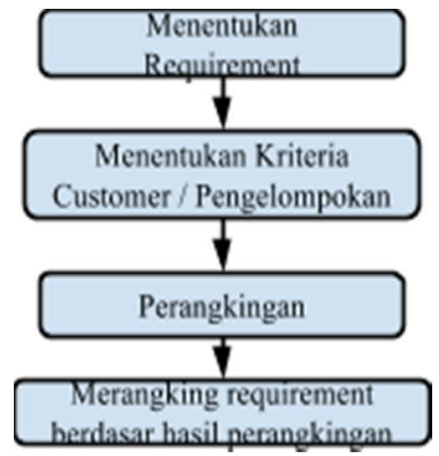

Gambar 4. Alur sistem ECV

Alur sistem ECV dimulai dari penentuan requirement dari stakeholder yang sudah dijelaskan di halaman sebelumnya. Lebih detailnya adalah sebagai berikut: 
1. Tentukan requirement apa saja yang hendak digunakan dalam menilai pelayanan dosen. Langkah ini sama seperti langkah Cumulative Voting yakni menentukan spesifikasi requirement. contoh dalam hal ini requirement adalah mahasiswa yang akan dikelompokan pada langkah no 2.

2. Mahasiswa sebagai customer dan requirement akademik terlebih dahulu dikelompokan dalam 4 kriteria. Spesifikasi Requirement:

a) berdasar tahun angkatan.

b) berdasar jumlah kehadiran.

c) berdasar status mata kuliah yang diambil.

d) berdasar lama waktu pengisian form.

3. Lalu masukan kedalam nilai secara bebas berdasar metode Analytic Hierarchy Process pada tabel matriks berpasangan seperti dibawah ini.

$\begin{array}{ccccc}\text { Kriteria } & \text { A } & \text { B } & \text { C } & \text { D } \\ \text { A } & 1 & (\mathrm{a}, \mathrm{b}) & (\mathrm{a}, \mathrm{c}) & (\mathrm{a}, \mathrm{d}) \\ \mathrm{B} & (1 / \mathrm{a}, \mathrm{b}) & 1 & (1 / \mathrm{c}, \mathrm{b}) & (\mathrm{b}, \mathrm{d}) \\ \mathrm{C} & (1 / \mathrm{a}, \mathrm{c}) & (\mathrm{c}, \mathrm{b}) & 1 & (\mathrm{c}, \mathrm{d}) \\ \mathrm{D} & (1 / \mathrm{a}, \mathrm{d}) & (1 / \mathrm{b}, \mathrm{d}) & (1 / \mathrm{c}, \mathrm{d}) & 1\end{array}$

Contoh pengisian

$\begin{array}{ccccc}\text { Kriteria } & \text { A } & \text { B } & \text { C } & \text { D } \\ \text { A } & 1 & 2 & 3 & 3 \\ \text { B } & 0.5 & 1 & 0.5 & 3 \\ \text { C } & 0.3333 & 2 & 1 & 3 \\ \text { D } & 0.3333 & 0.3333 & 0.3333 & 1\end{array}$

4. Setelah di isi, maka langkah selanjutnya adalah dinormalisasi dengan cara

a. Jumlahkan setiap elemen dengan jumlah masing-masing kolom.

\begin{tabular}{c|cccc} 
Kriteria & A & B & C & D \\
A & 1 & 2 & 3 & 3 \\
B & 0.5 & 1 & 0.5 & 3 \\
C & 0.3333 & 2 & 1 & 3 \\
D & 0.3333 & 0.3333 & 0.3333 & 1 \\
Jumlah & 2.1667 & 5.3333 & 4.8333 & 10 \\
b. Bagi Setiap elemen dengan \\
jumlah masing-masing kolom. \\
Lalu jumlahkan per kolom.
\end{tabular}

c. Cari rata-rata setiap kriteria. contoh hasilnya adalah seperti berikut.

\begin{tabular}{cccccccc} 
Kriteria & A & B & C & D & $\begin{array}{c}\text { Jumlah } \\
\text { Kolom }\end{array}$ & $\begin{array}{c}\text { Rata- } \\
\text { rata }\end{array}$ \\
A & 0.4615 & 0.375 & 0.6207 & 0.3 & 1.7572 & 0.4394 \\
B & 0.2308 & 0.1875 & 0.1034 & 0.3 & 0.8220 & 0.2054 \\
C & 0.1538 & 0.375 & 0.2069 & 0.3 & 1.0357 & 0.2589 \\
D & 0.1538 & 0.0625 & 0.0690 & 0.1 & 0.3583 & 0.9632 \\
Jumlah & 1 & 1 & 1 & 1 & 4 & 1 \\
\multicolumn{5}{c}{$\begin{array}{l}\text { Maka dapatlah bobot: } \\
\text { A }=0.4394\end{array}$} & C $=0.2589$ \\
B $=0.2054$ & D $=0.9632$ & & \\
\end{tabular}

5. Dari hasil bobot diatas, maka yang paling besar adalah bobot $\mathrm{D}$, untuk menguji konsitenitas maka kalikan bobot jumlah pada langkah 3a. Maka hasilnya adalah 4.262257 disebut nilai $\lambda$ (lamda) max.

6. Lalu cari nilai Consistency Index (CI) dengan menggunakan rumus $(\lambda \max -n) /(n-1) . n$ adalah banyaknya kriteria dalam contoh ada 4. maka hasilnya adalah (4.262257-4)/(4$1)=0.087419$ (CI)

7. Langkah selanjutnya adalah mencari nilai Consistency Ratio (CR) bagi nilai CI dengan nilai $\mathrm{CR}$ sesuai jumlah kriteria. dimana tabel IR adalah seperti berikut:

$$
\begin{array}{ccccccc}
1 & 2 & 3 & 4 & 5 & . . & 15 \\
0.00 & 0.00 & 0.58 & 0.90 & 1.12 & . . & 1.59
\end{array}
$$

Dimana jumlah $\mathrm{N}$ contoh diatas adalah 4, maka kita menggunakan tabel IR 4 yang bernilai

$$
\begin{array}{ll}
0.90 . & \\
\mathrm{CR}=\mathrm{CI} / \mathrm{CR}=0.087419 & / 0.90 \\
\mathrm{CR} & =
\end{array}
$$
disebut konsisten.

8. Sehingga susunan hirarki yang baru lengkap dengan bobot kriteria adalah:
$\mathrm{A}=0.4$
$\mathrm{B}=0.2$
$\mathrm{C}=0.3$
$\mathrm{D}=\quad 0.9$ atau 1 .
Dengan demikian jika nilai D
akan menjadi prioritas dalam 
perangkingan bobot dalam menentukan penilaian terhadap dosen. Jika D dimisalkan adalah nilai "kesiapan mengajar" maka dosen yang memiliki nilai kesiapan mengajar yang bagus, dosen tersebut dapat / mendekati penilaian sebenarnya.

\section{Implementasi Sistem}

a. Bagian Mahasiswa

Halaman kuisioner online

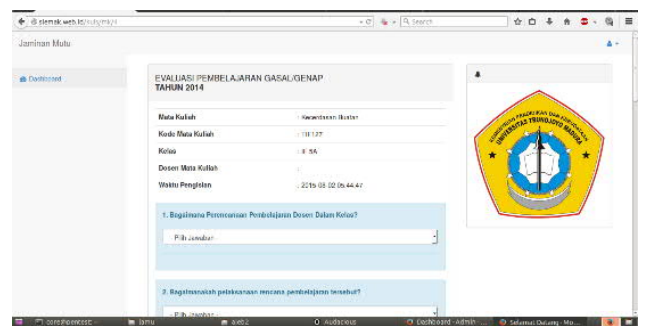

Gambar 6. Halaman Login Mahasiswa.

b. Bagian Admin Jaminan Mutu

Halaman Login Jaminan Mutu

(Jamu).

Halaman Key Performance Indicator

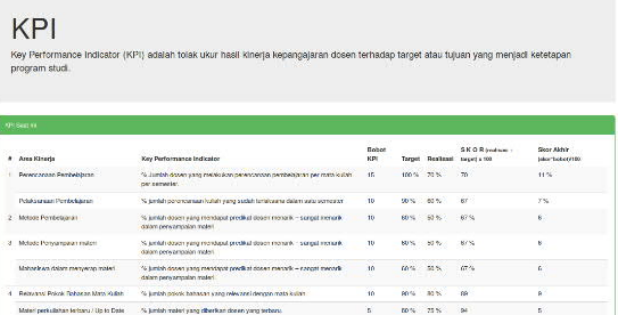

Gambar 7. Halaman Login Mahasiswa.

\section{SIMPULAN}

Kesimpulan yang dapat di ambil dari pembuatan Sistem Informasi Evaluasi Mutu Akademik Dan Proses Pembelajaran Studi Kasus: Program Studi Teknik Informatika Universitas Trunojoyo Madura Menggunakan Metode Enhanced Cumulative Voting. Adalah sebagai berikut;

1. Sistem informasi tersebut dapat membantu tim jaminan mutu dalam :

- Mengumpulkan data kuisioner.

- Mengukur tingkat kinerja dosen dalam kelas.

- Membandingkan perbedaan hasil dari 2 metode.

2. Membantu mempermudah mahasiswa dalam melakukan penilaian kinerja dosen dalam waktu dan media yang fleksibel.

3. Membantu menunjang program studi dalam akreditasi prodi karena telah memiliki data dan sistem pengukuran / measurament yang dapat diandalkan

\section{SARAN}

Saran untuk peningkatan kinerja aplikasi sistem informasi diatas adalaha sebagai berikut:

1. Waktu pengambilan data kuisioner yang digunakan tidak lagi dipenghujung semester namun bisa pada saat dosen mengajar.

2. Dapat menggunakan metode lain dan kriteria lain, semisal pendalaman kriteria lama pengisian form.

\section{DAFTAR PUSTAKA}

[1] Saaty, T.L. dan Vargas, L.G. (2001). Models, Methods, Concepts \& Applications of the Analytic Hierarchy Process, Kluwer Academic Publishers, Boston, MA.

[2] Agusa, K., Ohnishi, A. dan Ohno, Y. (1979). Verification of requirements description, in: The Proceedings of Twelfth Hawaii International Conference on System Science, Los Alamitos, CA.

[3] Leffingwell, D. dan Widrig, D. (2003). Managing Software Requirements: A Use Case Approach, Addison-Wesley, USA, 2nd edition, pp 124-125.

[4] Sahni, D. (2007). A Controlled Experiment on Analytical Hierarchy Process and Cumulative Voting, Master Thesis, Software Engineering Thesis no: MSE-2007-17, School of Engineering, Blekinge Institute of Technology, Sweden

[5] Prasetyo Eko, Pujianto Utomo. 2011. Clustering dan Pembobotan untuk Meningkatkan Metode Cumulative Voting. (Online) 